\title{
Formação docente em aplicativos Google Drive: desafios colocados à prática docente
}

\section{Teacher training in Google Drive applications challenges placed on teaching practice}

\author{
Ana Sampaio*, Lia Oliveira**, Elisabeth Pereira*** \\ *Instituto Federal do Amazonas, **Universidade Minho, ***Universidade Estadual do Ceará
}

\begin{abstract}
Resumo
Este trabalho pretende contribuir para abrir novas perspectivas, ao discutir, apresentar possibilidades e limitações quanto ao uso dos aplicativos Google Drive dirigido aos professores (formação continuada), afetos à Secretaria de Educação e Qualidade de Ensino e no Instituto Federal do Amazonas. A metodologia adotada prevê um estudo de caso exploratório-descritivo. Quanto aos procedimentos e técnicas vai ser realizada, pesquisa bibliográfica, intervenção por via de oficinas a aproximadamente 20 professores das componentes curriculares Matemática e Língua Portuguesa. Espera-se que os docentes ampliem a produção do conhecimento e a melhoria do processo ensino e aprendizagem com a adoção dos aplicativos da Google.

Palavras-chave: aprendizagem, aplicativos Google, colaboração, formação continuada, interação
\end{abstract}

\begin{abstract}
This paper intends to contribute to open up new perspectives in discussing, presenting possibilities and limitations regarding the use of the Google Drive applications directed to teachers (continuing education), affections to the Education and Teaching Quality Department and the Federal Institute of Amazonas. The methodology adopted foresees an exploratory-descriptive case study. As for the procedures and techniques will be carried out, bibliographical research, intervention by means of workshops to approximately 20 teachers of the curriculum components Mathematics and Portuguese Language. Teachers are expected to expand knowledge production and improve the teaching and learning process through the adoption of Google applications.

Keywords: learning, google applications, collaboration, continuing education, interaction
\end{abstract}

\section{Formação dos docentes quanto ao uso das tecnologias}

A resistência quanto ao uso das novas tecnologias por parte de alguns docentes demonstra o desafio da quebra de paradigma e aceite das transformações no processo educacional. Portanto, Sathler, Josgrilberg, Azevedo (2008: 12), afirmam "a ocorrência desta situação está no fato de alguns docentes não compreenderem o avanço e ganho com essas mudanças".
De acordo com Pimentel (2007: 10), "para a eficiência e eficácia da formação e necessário organizar todas as ações envolvidas nessa capacitação, para suprimir as dificuldades que possam ocorrer durante o processo, tais como: gestão, resistência por parte dos educadores, falta de infraestrutura, falta de recursos e paradigmas educacionais". As barreiras com as quais os docentes se deparam na formação inicial, quanto ao uso dos artefatos tecnológicos é, justamente, a falta de familiaridade com as tecnologias. Muitos formadores se deparam com professores que, na maioria das vezes, nem sequer sabem utilizar um computador para formatar um texto, fazer uma apresentação ou criar uma planilha. Esse fato oportuniza que eles criem aversão a este universo e não aceitem utilizá-lo, afinal, no modelo de educação tradicional, onde a compreensão do papel do professor é a de detentor do conhecimento, o uso da tecnologia não se faz necessário, porém, agora, com o avanço destas tecnologias, ele passa a ser um mediador do processo de ensino e aprendizagem fazendo com que os seus alunos possam ser produtores de conhecimento e não apenas receptores. (Behar, 2009; Sacool, Schlemmer, Barbosa, Hahn, 2011).

Como já apontado acima, existem vários entraves a serem superados na formação dos docentes quanto ao uso de tecnologias, por isso, é imprescindível ressaltar que o uso das tecnologias na educação não possui finalidade em si mesmo, mas tem por objetivo servir de meio, criar novas possibilidades e potencializar as já existentes, dentro do processo de ensino e aprendizagem, na construção do conhecimento do docente e do discente. Mas, para que as barreiras sejam superadas mais facilmente, o processo de formação a ser elaborado deverá fazer uso de ferramentas que tenham como uma de suas marcas o desenvolvimento das competências do domínio tecnológico para o docente e que represente uma oportunidade de alteração do perfil de resistência à tecnologia; é nesse ponto que a escolha pelo uso dos aplicativos da Google para esse processo de formação. 


\section{Origem da Google}

O significado da empresa Google deriva de palavras que são iguais cuja intencionalidade é surtir efeito publicitário e humorístico com o termo "googol", originado pelo matemático Edward Kasner da Universidade da Columbia que desenvolveu o número seguido por cem zeros, que não fosse infinito, dando origem ao nome da empresa americana Google.

O nome reflete na informação e missão que a empresa Google pretende atingir: organizar as informações do mundo e torná-las mundialmente acessíveis e úteis, ou seja, receber e desenvolver uma série de produtos e serviços baseados na internet.

Desta feita, (Mendelson, 2011:34), "os aplicativos da Google simplificam o compartilhamento de informações e a obtenção de resultados como Google Drive que oferece à educação cenários para o desenvolvimento de experiências e desafios, ajudando as pessoas a se comunicarem e a trabalharem em conjunto mais facilmente".

De acordo com os teóricos Bottentuit Junior, Lisbôa, e Coutinho (2011:30) "confirmam que os aplicativos desenvolvidos pela Google permitem aos seus usuários o desenvolvimento de várias competências em diferentes níveis tais como: a escrita online (pessoal ou colaborativa), estímulo visual através de imagens e o auditivo através da gravação e reprodução de arquivos em formato de som".

Essa variedade de aplicativos que a Google oferece permite aos utilizadores realizarem, praticamente quase todas as atividades de criação, edição, gravação, divulgação e armazenamento de arquivos diretamente da web.

Diante do exposto, apresentaremos, a seguir, alguns dos aplicativos disponíveis na plataforma Google e suas funcionalidades, destacando aquelas que julgamos de maior relevância para esta pesquisa, uma vez que, o objeto de estudo é analisar as funções que a plataforma Google pode permitir em processos de ensino e aprendizagem como promotor de ações colaborativas no universo da interatividade virtual.

\section{Aplicativos da Google suas potencialidades e aplicabilidade no ensino e aprendizagem dos professores}

Nesse contexto, quando tratamos de aprendizagem construtiva e significativa na educação quanto ao uso das novas tecnologias digitais, é preciso que tenhamos uma perspectiva inovadora de ensinar. Portanto, aprender em rede, de forma colaborativa, investigativa e interativa com a utilização dos aplicativos da Google, especificamente com os recursos Google Drive é ir além do simples uso para sua significação ou ressignificação nas atividades pedagógicas de ensino e aprendizagem. Assim, o foco principal da utilização dos aplicativos da Google não é só ofertar um ambiente que seja mediado para o ensino, mais também de aprendizagem colaborativa e interativa, para orientar e gerar conhecimentos sobre as ferramentas que estão disponíveis para comunicação e prática pedagógica tanto para professores quanto para alunos, visando desenvolvimento do aluno em múltiplos planos, além de, adquirir co-construção do conhecimento, bem como, proporcionando aos professores novas formas de ensinar.

A importância de se utilizar o Google Drive nas atividades pedagógicas vai além do armazenamento de arquivos no servidor da Google, mais também como compartilhamento das informações adquiridas pelo usuário.

O Google Drive guarda um leque de aplicativos de produtividade, que oferece a edição de documentos, folhas de cálculo, apresentações e avaliações on-line.

Para compreendermos as potencialidades das ferramentas Google Drive associada às estratégias pedagógicas, iremos comentar a funcionalidade de cada um dos aplicativos, conforme observar-se nos parágrafos.

Desta feita, o Google Documentos tem como aplicabilidade a edição colaborativa de um mesmo documento, oportunizando trabalho coletivo, e também, a publicação on-line de versões dinâmicas, incluindo folhas de cálculos e apresentações colocando uma simples linha de código na página web desejada.

Enquanto que, o Google Planilhas é utilizado para acompanhar os trabalhos dos alunos; criar cartões com vocabulários, ou até mesmo ajudar os alunos a documentar suas experiências cientificas através da edição colaborativa de planilhas eletrônicas.

Contudo, o Google Apresentação engloba a edição colaborativa de slides para apresentação de grupo, podendo os alunos usar o aplicativo para criar a sua parte da apresentação, em seguida, integrá-las a apresentação principal.

Com relação o Formulário da Google utilizado de forma prática e integrada, promovendo a colaboração e a criatividade através de atividades em grupo, desenvolvendo também a comunicação de forma aprimorada e em tempo real.

Portanto, nesse contexto, a tecnologia pode ser catalizadora de novas experiências proporcionando aprendizagens diversas.

\section{A utilização das ferramentas da Google a práxis pedagógica}

Com o desenvolvimento tecnológico os alunos passaram a exigir novos métodos de ensino e aprendizagem, a presença dos computadores cada vez mais frequente na vida cotidiana dos alunos, permite a inquietação e insatisfação dos mesmos nas aulas explicativas, fazendo necessário que os professores tenham domínio de novas tecnologias de ensino.

A pesquisa de Tardiff sobre a inserção das tecnologias na educação demonstra diferenças quanto aos objetivos e finalidades, de modo particular, mostra que as tecnologias na educação devem contribuir para o aprendizado dos sujeitos, sobrepondo à dimensão ontológica à técnica em sua formação.

A presença das tecnologias na sala de aula é um dos exemplos de como a cibercultura é uma parte inerente ao nosso cotidiano.

A utilização dos aplicativos da Google via redes digitais apresentam facilidade de comunicação e aproximação entre os sujeitos, levando-se a incorporação de abordagens pedagógicas e consequentemente, aplicar 
esse conhecimento à educação favorecendo à co-construção do conhecimento. Além de, promover a integração, participação, colaboração e interatividade de alunos e professores consolidando a inovação pedagógica potencializada para aplicação de recursos digitais para educação.

Dessa maneira, o professor aprende com o aluno e o aluno aprende com o professor, numa relação horizontal com diálogo criando-se possibilidade de aprendizagem em rede.

Nesta perspectiva, Ponte afirma que, “[...] as tecnologias em redes proporcionam a existência de ambientes intermediários entre mim e os outros, que permitem fundar comunidades reais, no sentido em que não existe presença física." (2000: 69).

Assim sendo, o conhecimento não são somente aquisição e apropriação de conteúdos, mas também aprender a transformá-los em saberes para a vida e à participação na sociedade em que está inserido. Essa visão de uma formação integral do aprendiz deve estar intrínseca na prática docente.

\section{Método}

Nesta secção explicitam-se as opções metodológicas e descreve-se o desenho do estudo.

\section{Tipo de estudo}

A pesquisa apresentada neste artigo tem como metodologia do tipo descritivo e exploratório, através de levantamento bibliográfico, revisão de literatura e intervenção no terreno por via de oficinas de formação de forma colaborativa com o grupo pesquisado $\mathrm{e}$ entrevistas. Ou seja, assume a forma de estudo de caso (Gil, 2002).

Foi concebida uma oficina de formação continuada lecionada a cerca de 20 professores no espaço da atuação docente, em seu ambiente profissional, que é à escola. Buscou-se, de forma colaborativa com os docentes, discutir de que forma os professores se apropriam dos aplicativos Google Drive, durante e logo após a oficina dedicada ao assunto.

Sendo este o caminho a percorrer, buscaremos através de técnicas específicas responderem as questões que a pesquisa propõe que são as seguintes:

01) Oportunizar a reflexão sobre o potencial educativo das tecnologias digitais de rede.

02) Investigar as práticas pedagógicas efetivas que conduzem ao processo ensino aprendizagem, verificando a função e a importância dos recursos tecnológicos no processo.

03) Avaliar a usabilidade das ferramentas da Google pelos docentes em processos de ensino e aprendizagem como promotor de ações colaborativas no universo da interatividade.

O estudo foi desenvolvido na educação básica com os docentes ministrantes das componentes curriculares Matemática e Língua Portuguesa com aproximadamente 20 professores, sendo18 da Secretaria de Educação e Qualidade de Ensino - SEDUC e 2 do Instituto Federal do Amazonas - IFAM-CMZL que estão participando das oficinas no Estado do Amazonas, município de Manaus.
Por questões éticas, a entrevista e a aplicação dos questionários foram ministradas de forma anônima, sendo que, para os questionários, foram utilizados aplicativos do formulário Google no formato online e enviados para os e-mails dos docentes envolvidos na pesquisa, contendo as seguintes informações: perfil dos docentes, perfil tecnológico e didático pedagógico.

\section{Procedimentos, técnicas e instrumentos de recolha de dados}

A proposta da pesquisa foi organizada em 6 (seis) momentos, conforme descrição abaixo. As técnicas e instrumentos de recolha de dados a usar serão os adequados a cada momento.

No primeiro momento, foi dialogada com a gestão da escola, equipe pedagógica e os professores a intenção de realizar uma oficina utilizando os recursos Google Drive com os professores do ensino fundamental e médio visando analisar as métricas de ensino adotadas pelos professores, a forma de absorção dos conteúdos pelos alunos, nas disciplinas de português e matemática e, as estratégias dos professores para ir além de atender a contento o processo de ensinar buscando novas formas de inovar em sala de aula.

No segundo momento, antes da realização da oficina de formação, aplicou-se da técnica do inquérito por questionário contendo 16 (dezesseis) perguntas distribuídas em abertas e fechadas para saber quais os conhecimentos e habilidades dos docentes com as Tecnologias de Informação e Comunicação - TIC, especificamente com os aplicativos Google.

No terceiro momento, realizou-se oficina de formação aos docentes das componentes curriculares Matemática e Língua Portuguesa nos turnos Matutino e Vespertino, com a duração de 5 (cinco) dias, uma vez por semana, com duração de 4 (quatro) horas cada, totalizando 20 (vinte) horas. A oficina versa a utilização dos aplicativos Google Drive como forma de interação, colaboração e integração no desenvolvimento de atividades letivas.

Os professores tiveram a oportunidade de explorar os aplicativos da Google durante um mês para produção de materiais e atividades a serem aplicadas na sala de aula com os alunos após a finalização da oficina.

No quarto momento, após o término da oficina de formação, aplicou-se da técnica do inquérito por questionário contendo 14 (quatorze) perguntas, distríbuidas em abertas e fechadas e por entrevistas para saber quais os aplicativos Google Drive que foram bem-sucessidas no processo ensino e aprendizagem dos discentes.

No quinto momento, em fase de andamento, como produto final da oficina os professores irão produzir, em pares, um projeto de implementação de atividades com os aplicativos Google Drive, direcionados à sua disciplina com seus alunos. No final da oficina, os mesmos, apresentarão estes projetos que deverão contemplar a motivação e ações que oportunizem novas práticas e metodologias para o contexto escolar. Sendo motivo de observações os docentes pela investigadora com registo de notas de campo. 
No sexto momento, análise e discussão dos dados com tabulação por meio da estatística descritiva, sendo as variáveis utilizadas para avaliação do tipo qualitativa e produção de gráficos utilizando como recurso a ferramenta Excel.

\section{Resultados esperados}

Nesta pesquisa apresentaremos diversos aplicativos da Google Drive que podem ser utilizadas em contexto educativo, visando tornar o ato de aprender e de ensinar mais atraente e significativo, pois, "[...] ensinar ou aprender, na era da informação, exige mudanças nos paradigmas de ensino. O importante é utilizar as tecnologias de forma que nos ajudem a aprender, levando-nos a transformar informação em conhecimento" (Cruz: 2008), uma vez que lança mãos do universo vivenciado pelas maiorias dos jovens, a que Prensky (2001) denomina de "nativos digitais", portanto, espera-se que os docentes ampliam a produção do conhecimento e a melhoria do processo ensino aprendizagem buscando conhecer e estar consciente de que a adoção dos aplicativos da Google Drive tenha reflexos na sua prática docente e nos processos de aprendizagem.

\section{Referências}

Behar, P. A. (2009). Modelos pedagógicos em educação à distância. Atmed Editora.

Bottentuit Junior, J. B., Lisbôa, E. S., \& Coutinho, C. P. (2011). Google Educacional: utilizando ferramentas Web 2.0 em sala de aula. EducaOnline,5(1Janeiro/Abril), 17-44. http://latec.ufrj.br/revistas/index.php?journal=educaon line $\&$ page $=$ article \&op $=$ view $\&$ path []$=93 \&$ path []$=81$.

Gil, A. C. (2002). Como elaborar projetos de pesquisas. São Paulo, 5(61), 16-17.

Lessard, C. (2012). O ofício de professor: história, perspectiva e desafios internacionais. Editora Vozes Limitada.

Maia, C., \& Mattar, J. (2008). ABC da EaD: a educação à distância hoje. Pearson Prentice Hall.

Marcos, J., \& Cruz, O. (2008). Processo de ensino-aprendizagem na sociedade da informação. Educ. Soc, 29(105), 1023-1042.

Mendelson, E. (2011). Android honeycomb Apps. PC Magazine Digital Edition, 30(4), 1-72. http://www.periodicos.capes.gov.br.ez61.periodicos.c apes.gov.br/

index.php?option $=$ com_pmetabusca\& $\mathrm{mn}=88 \& \mathrm{smn}=8$ $8 \&$ type $=$ m\&metalib $=a H R 0 c D o v L 2 J 1 \mathrm{c} 2$

NhZG9yLnBlcmlvZGlj.

Pimentel, F. S. C. (2007). Formação de Professores e Novas Tecnologias: possibilidades e desafios da utilização de webquest e webfólio na formação continuada. Rio de Janeiro: DECEx. http://www.ensino.eb.br/portaledu/conteudo/artigo 778 $0 . p d f>$.

Ponte, J. P. Tecnologia da informação e comunicação na formação de professores: que desafios? Revista Ibero Americana de Educação, Lisboa-Portugal, n.24, pp. 63-90, sept./Dic., 2000.
Prensky, M. (2001). Digital natives, digital immigrants part 1.On the horizon, 9(5), 1-6. http://www.marcprensky.com/writing/Prensky\%20\%2 0Digital\%20Natives, \%20Digital\%20Immigrants\%20\%20Part1.pdf.

Sacool, A., Schlemmer, E., Barbosa, J., \& Hahn, R. (2011). M-learning e u-learning: novas perspectivas da aprendizagem móvel e ubíqua. Pearson. Prentice Hall. São Paulo.

Sampaio, M. N., \& Leite, L. S. (2004). Alfabetização tecnológica do professor. Vozes.

Sathler, L., Josgrilberg, F., \& Azevedo, A. B. D. (2008). Educação a distância uma trajetória colaborativa. São Paulo: Universidade Metodista de São Paulo.

Tardif, M (2012). Saberes docentes e formação profissional. Editora Vozes Limitada.

Thiollent, M. (2011). Metodologia da pesquisa - ação. In Metodologia da pesquisa-ação. Cortez. 